\title{
Desenho da Figura Humana: avaliação da imagem corporal na deficiência física ${ }^{1}$
}

\author{
Diego Rodrigues Silva², Eliana Herzberg \\ Universidade de São Paulo, São Paulo-SP, Brasil
}

\section{RESUMO}

O Desenho da Figura Humana (DFH) possibilita avaliar a psicodinâmica e a imagem corporal. Questiona-se sua aplicação em pessoas com deficiência física com problemas orgânicos e sociais que incidem sobre a imagem corporal. Buscou-se revisar e discutir a literatura do DFH sobre essa população, tendo sido encontrados 15 trabalhos entre 1949 e 2016. Esses estudos contemplam a avaliação da imagem corporal, a comparação entre grupos e as críticas em relação ao procedimento. Foram encontrados, nas figuras, tratamento inusual dos membros e do tronco e assimetrias, indicando dificuldades no contato com o ambiente e integridade da imagem corporal. Discutiu-se a relação entre os prejuízos motores e a projeção de fato nos desenhos, e ressaltaram-se cuidados para evitar vieses nas análises. Concluiu-se que o DFH oferece contribuições clínicas e científicas, e apresenta questões a serem discutidas que necessitam de atualização da literatura. Pesquisas podem contribuir para um futuro parecer favorável à técnica projetiva.

Palavras-chave: deficiente físico; desenho de figuras humanas; imagem corporal.

\section{ABSTRACT - Draw-a-Person Test: Body image evaluation in physical disability}

Draw-a-Person Test (DPT) evaluates psychodynamics and body image. Its use on people with physical disabilities is controversial, for there are organic and social issues that concern their body image. This article aims to review and discuss the DPT literature regarding this population. In a review, 15 papers from 1949 to 2016 were found that encompassed body image evaluation, group comparison and critiques concerning the technique. Unusual treatment of the limbs and upper body, and asymmetry were reported in the drawings, indicating difficulties with contact with the environment and body image integrity. Questions about the relationship between motor damage and a noticeable projection in the drawings were raised, warning professionals about the care needed to avoid biases in interpretations. The paper concludes that DPT provides clinical and scientific contributions, and raises questions to be discussed that need an update in the literature. Further studies may contribute to validate the use of the HFD as a projective technique.

Keywords: physically disabled; human figure drawing; body image.

\section{RESUMEN - Dibujo de la Figura Humana: evaluación de la imagen corporal en la deficiencia física}

El Dibujo de la Figura Humana (DFH) permite evaluar la psicodinámica y la imagen corporal. Se cuestiona su aplicación en personas con deficiencia física en las que hay problemas orgánicos y sociales que inciden en la imagen corporal. Se buscó revisar y discutir la literatura del DFH en esta población, habiéndose encontrado 15 trabajos entre 1949 y 2016. Estos trabajos consideran la evaluación de la imagen corporal, la comparación entre grupos y las críticas con relación al procedimiento. Se encontró un las figuras un tratamiento inusual de los miembros y del tronco y asimetrías, indicando dificultades en el contacto con el ambiente y la integridad de la imagen corporal. Se discutió la relación entre perjuicios motores y la proyección de hecho en los dibujos y se destacaron cuidados para evitar sesgos en los análisis. Se llegó a la conclusión que el DFH ofrece contribuciones clínicas y científicas, presenta puntos a ser discutidos y que necesita actualización de la literatura. Las investigaciones pueden contribuir para un futuro dictamen favorable de esta técnica proyectiva. Palabras clave: deficiente físico; diseño de figuras humanas; imagen corporal.

O uso do desenho enquanto técnica de avaliação psicológica geralmente compreende avaliação da maturidade cognitiva e da personalidade. Neste segundo caso, diferentes variáveis de desenhos são utilizadas para fornecer características de personalidade. Esta última definida como representação de aspirações, preferências, modos de se relacionar, ideias, padrões, hábitos e atitudes
(Andrade, 2014). Autores como Machover (1949) e Van Kolck (1984) sistematizaram uma proposta de avaliação da imagem corporal por meio do desenho de figuras humanas, relacionando determinados traços a características pessoais. Dessa forma, foi desenvolvida uma técnica que avalia especificidades da imagem corporal e explora características da personalidade.

${ }^{1}$ Parte desta discussão foi apresentada na modalidade de painel no VII Congresso Brasileiro de Avaliação Psicológica. Este trabalho é parte da dissertação de mestrado do primeiro autor, sob orientação da segunda autora, em andamento no Programa de Psicologia Clínica do Instituto de Psicologia da Universidade de São Paulo, com apoio da Coordenação de Aperfeiçoamento de Pessoal de Nível Superior. Agradecimentos a Maria Eulalia e Daniel Pequeno pelas traduções. ²Endereço para correspondência: Praça Miguel Ortega, 50, Parque Assunção, 06754-160, Taboão da Serra-SP, Brasil. E-mail: silva.diego@usp.br 
Machover (1949) enfatiza que quando alguém desenha, o faz segundo algumas referências, tais como o investimento sobre os órgãos (sensações, percepções e emoções), a percepção da imagem corporal, o próprio corpo e o Eu, com suas projeções e introjeções, evidenciando a relação entre o desenho e a personalidade. Desenhar expressaria, então, aspectos conscientes e inconscientes do sujeito. Para a autora, os desenhos variam em função da idade, da habilidade e da cultura na qual estão inseridas as pessoas. Assim, a cultura ganha importância, pois determinadas posturas e partes do corpo adquirem significados dependendo do meio social.

Entende-se portanto a imagem corporal como uma experiência de unidade, uma forma de esquematização e figuração do corpo advinda das experiências. É uma forma de organização e síntese do sujeito (Schilder, 1950/1980). Dolto (1984/2015) e Nasio (2009) equiparam a imagem corporal à noção de $\mathrm{Eu}$, justamente enfatizando como esse centro ordenador advém do corpo.

Schilder (1950/1980) demonstra que determinados modelos posturais são moldados por afetos, assim como afetos podem disparar uma série de tensões musculares que configuram uma postura característica e compartilhada no meio social como um determinado afeto. Tais modelos seriam mediadores das relações que se estabelecem, visto que cada um apresenta reações específicas. Circunscreve-se, assim, que nos desenhos se torna possível verificar modelos posturais, além da forma como cada um significa e se vale de tais modelos, relacionando o corpo orgânico, os componentes psíquicos (idealizações, desejos, projeções e introjeções) e o acervo de sentidos advindos do meio social. Tal compreensão detalha o que na literatura é denominado "personalidade", abrangendo seu sentido.

[...] acredito que o modo como as crianças desenham as figuras humanas realmente reflete o conhecimento e a experiência motora que têm da imagem corporal. No mínimo expressam a imagem mental que possuem do corpo humano, e a imagem corporal é tanto imagem mental quanto percepção. (Schilder, 1950/1980, p. 95)

Valendo-se da observação do simbolismo atribuído ao corpo e de sua contribuição para a prática clínica, Machover (1949) desenvolveu a técnica do Desenho da Figura Humana (DFH), entendendo-o como um veículo de expressão das necessidades e dos conflitos do corpo, assim como a linguagem e as demais expressões. Trata-se de uma atividade simples, em que são oferecidos folha branca, lápis preto $\mathrm{n}^{\circ} 2$, borracha e apontador, e solicita-se que seja feito o desenho de uma pessoa. Após o término, pede-se que um segundo desenho de uma pessoa do sexo oposto seja feito. Em seguida, realiza-se um inquérito sobre o desenho do mesmo sexo do paciente, que busca esclarecer os conteúdos e abrir espaço para a associação livre. A autora postulava que somente com essas associações se tornava possível uma interpretação, e assim acesso aos conteúdos singulares, embora não tenha deixado claro se o inquérito era realizado sistematicamente para as duas figuras. Ainda assim, dadas as regularidades em diferentes desenhos quanto à significação de cada parte do corpo, possíveis relações foram formalizadas, constituindo, segundo sua proposta, guidelines para a análise.

Seguindo Machover, Van Kolck (1984) insere a questão das relações que constituem a imagem corporal, o que muda a compreensão de uma representação especular para uma construção singular calcada em experiências.

A imagem corporal é uma unidade, unidade adquirida e não dada, e pode ser destruída. Implica um esforço contínuo para dar uma estrutura a algo dinâmico [...]. Sendo o produto de um organismo vivo como um todo, uma alteração em uma parte dele por uma doença ou mal físico, por exemplo, não introduzirá modificações na imagem corporal apenas a essa parte; a mudança será geral, pois resultará de novas relações consigo mesmo e com os outros. (Van Kolck, 1984, p. 15, grifos da autora)

Desde Machover (1949), há menção sobre estudos do DFH em diferentes populações, como pacientes psicóticos e pessoas com deficiência física. Sobre estes últimos, a autora aponta que os resultados foram surpreendentes e que os desenhos variaram em relação ao tempo e à extensão das doenças que levaram à deficiência. Considera-se deficiência como anormalidade de estrutura e de função fisiológica ou anatômica. Essa alteração pode ser completa ou parcial de um ou mais segmentos do corpo humano, acarretando o comprometimento de uma função. O ambiente é um mediador da deficiência, visto que uma função só pode ser avaliada como eficaz ou ineficaz por meio de sua interação com o meio. Nesse ponto, levando em conta o histórico da deficiência e as construções de "normal" e "desviante", o ambiente traz dificuldades, inclusive na construção da autoimagem e da imagem corporal, acarretando, por sua vez, em dificuldades nas relações (Macedo, 2008).

Diante das questões reportadas anteriormente e da importância do instrumento como ferramenta clínica e científica, este artigo buscou revisar e analisar a literatura da avaliação por meio do desenho da figura humana em pessoas com deficiência física. Dado o enfoque do instrumento sobre o corpo e suas significações singulares, o desenho é considerado um recurso interessante a ser explorado, e que pode trazer contribuições para avaliações e intervenções em pessoas com deficiência física. Da mesma forma, o artigo visou contribuir para que a técnica possa obter, no futuro, parecer favorável como técnica projetiva pelo Conselho Federal de Psicologia. 


\section{Método}

Para a revisão da literatura foram utilizados os descritores "physical disability", "human figures drawing" e "body image", indexados ao Thesaurus do PsycNET e da Terminologia do BVS-Psi. As bases consultadas foram PsycNET, Web of Science, Scopus, Biblioteca Virtual em Saúde (BVS) e SIBiUSP, permitindo uma pesquisa com os termos em inglês (idioma de indexação). Ademais, na base BVS também foi realizada uma pesquisa em português com os termos "deficiência física", "desenho de figuras humanas" e "imagem corporal" para verificar a existência de possíveis trabalhos não localizados com os termos em inglês.

Primeiramente foi realizada uma busca nas bases utilizando os descritores citados. Com uma pré-seleção do material, observou-se que se tratava de uma literatura restrita quanto ao número de artigos, predominantemente anteriores aos anos 1980 e de difícil acesso. Como critérios de inclusão, foram selecionados artigos em português, inglês, francês e espanhol; assim como os que apresentavam trabalhos sobre desenhos de figura humanas, independentemente da técnica, do método e dos objetivos propostos. Buscou-se, dessa forma, abranger o maior número de trabalhos utilizando o procedimento, independentemente de seu referencial. Como critérios

3Vale citar que quando se trata de pesquisas sobre deficiência há a problemática em relação ao termo em inglês. É dado histórico que se reflete na literatura, de modo que para a pesquisa foi preciso buscar por physical handcap, disability e disorder, sendo a segunda opção a mais frequente nas pesquisas atuais. de exclusão, não foram considerados artigos que não utilizaram o recurso gráfico ou que tratassem de outras deficiências para além da física. Não foram estabelecidos critérios quanto ao ano da publicação, de modo a abranger a maior parte da literatura até o ano de 2016, para assim abarcar os dados existentes e poder conjecturar o estado da arte do tema na literatura. Para os artigos não acessíveis na íntegra $(n=5)$, foram considerados seus resumos, de modo que os trabalhos de acesso completo foram descritos e discutidos de maneira mais detalhada.

\section{Resultados e Discussão}

Foram encontrados 16 trabalhos em que o desenho foi utilizado, entre eles artigos científicos e uma dissertação de mestrado. A fim de sistematizar a literatura encontrada, os dados foram organizados em uma tabela (Tabela 1) na qual constam a referência, o objetivo, seu método e os principais resultados, estabelecidos enquanto categorias de análise e dispostos de modo a melhor ilustrar os principais dados dos trabalhos e apresentá-los seguindo a ordem cronológica. Os artigos em que apenas o resumo se encontrava disponível estão sinalizados na tabela com “ $\star$ ” antes do nome.

Os trabalhos se distribuem entre os anos de 1949 e 2007, com maior número $(n=5)$ na década de 1970. Tal dado revela que se trata de uma literatura antiga e que perdeu sua expressividade ao longo dos anos. Vale citar que na pesquisa inicial, antes da pré-seleção, foram encontrados artigos atuais - como Soto \& Pérez (2015) - que buscavam

Tabela 1

Síntese dos Resultados Obtidos

\begin{tabular}{|c|c|c|c|}
\hline Referência & Objetivo & Método & Resultados \\
\hline $\begin{array}{l}\text { Campos, } \\
\text { Avoglia, e } \\
\text { Custódio } \\
\text { (2007) }\end{array}$ & $\begin{array}{l}\text { Verificar a } \\
\text { representação do } \\
\text { próprio corpo em } \\
\text { indivíduos com } \\
\text { deficiência física, } \\
\text { especificamente } \\
\text { com paraplegia não } \\
\text { congênita. }\end{array}$ & $\begin{array}{l}\text { Dois adultos com } \\
\text { paraplegia não congênita. } \\
\text { Entrevista e DFH } \\
\text { (Van Kolck). }\end{array}$ & $\begin{array}{l}\text { Divisão do corpo em duas partes. } \\
\text { Sentimentos de falta de confiança em si, } \\
\text { nostalgia, atitude de expectativa diante da } \\
\text { vida e desejo de obter aprovação social. }\end{array}$ \\
\hline Scherb (1998) & $\begin{array}{l}\text { Investigar aspectos } \\
\text { psicossociais da } \\
\text { deficiência física pela } \\
\text { autoimagem. }\end{array}$ & $\begin{array}{l}30 \text { pessoas adultas com } \\
\text { lesão medular adquirida. } \\
\text { Questionário e DFH } \\
\text { (Machover). }\end{array}$ & $\begin{array}{l}\text { Possível observar a influência maior de } \\
\text { fatores sociais do que orgânicos na percepção } \\
\text { da própria deficiência e da autoimagem; } \\
\text { dificuldades já conhecidas de inserção do } \\
\text { deficiente físico no mercado de trabalho; } \\
\text { sentimento de desorientação experimentado } \\
\text { perante as diferentes expectativas sociais } \\
\text { (reais e imaginárias). }\end{array}$ \\
\hline $\begin{array}{l}\text { Krampen } \\
(1985)\end{array}$ & $\begin{array}{l}\text { Comparar desenhos } \\
\text { de crianças com e } \\
\text { sem deficiência física. }\end{array}$ & $\begin{array}{l}59 \text { crianças (6-12 anos) } \\
\text { com deficiência física } \\
\text { comparadas a } \\
25 \text { crianças ( } 3-6 \text { anos) } \\
\text { do grupo controle. } \\
\text { Desenhos livres. }\end{array}$ & $\begin{array}{c}\text { Diferença significativa no terceiro estágio do } \\
\text { desenvolvimento do grafema, na produção } \\
\text { de grafemas simétricos. Crianças com } \\
\text { deficiência mais lentas, sendo explicado pelo } \\
\text { esquema corporal. }\end{array}$ \\
\hline
\end{tabular}


Tabela 1 (continuação)

Síntese dos Resultados Obtidos

\begin{tabular}{|c|c|c|c|}
\hline Referência & Objetivo & Método & Resultados \\
\hline $\begin{array}{l}\text { Van Kolck } \\
\text { (1973) }\end{array}$ & $\begin{array}{l}\text { Sistematizar dados } \\
\text { da literatura sobre } \\
\text { imagem corporal em } \\
\text { situações específicas. }\end{array}$ & $\begin{array}{l}\text { Revisão da literatura: DFH } \\
\text { e pessoas com deficiência } \\
\text { física, hipertensão, } \\
\text { asma, problemas } \\
\text { gastrointestinais, obesos, } \\
\text { problemas cardíacos, } \\
\text { problemas emocionais e } \\
\text { surdos-mudos. }\end{array}$ & $\begin{array}{l}\text { Deficiências mais expressivas com menores } \\
\text { problemas na imagem corporal em relação às } \\
\text { moderadas; em amputados a problemática } \\
\text { não apareceu no desenho, possível relação } \\
\text { com a negação; possível relação entre } \\
\text { maior nível de dificuldades emocionais e } \\
\text { menor QI; 62\% de acerto de juízes blindview } \\
\text { para diferenciar desenhos de crianças } \\
\text { com e sem deficiência, critérios: distorção, } \\
\text { sombreamento, tamanho, omissão de } \\
\text { membros, expressão direta da deficiência. }\end{array}$ \\
\hline $\begin{array}{l}\text { Van Kolck e } \\
\text { Van Kolck } \\
(1972)\end{array}$ & $\begin{array}{c}\text { Sistematizar dados } \\
\text { da literatura sobre } \\
\text { o DFH em casos } \\
\text { especiais. }\end{array}$ & $\begin{array}{c}\text { Revisão da literatura: } \\
\text { DFH e crianças com } \\
\text { problemas orgânicos, } \\
\text { jovens delinquentes, } \\
\text { idosos e no estudo da } \\
\text { "dependência de campo". }\end{array}$ & $\begin{array}{l}\text { Presença de traços de preocupação sexual, } \\
\text { desproporção das partes do corpo, pobre } \\
\text { síntese, mais detalhes em partes conflitivas } \\
\text { específicas; DFH expressando diretamente } \\
\text { a deficiência (omissão, presença de órteses, } \\
\text { discrepância no tamanho dos membros, } \\
\text { junção imprópria com o tronco); presença } \\
\text { de figuras inclinadas, extremidades } \\
\text { desproporcionais, alteradas ou rasuradas e } \\
\text { junções inapropriadas com o tronco. }\end{array}$ \\
\hline
\end{tabular}

Johnson

(1972)

Comparar os desenhos de pessoas se recuperando da poliomielite com grupo controle.

Comparar a imagem

*Weininger, Rotenberg, e Henry (1972)

${ }^{*}$ Manganyi

Abercrombie e Tyson (1966)

*Wysocki e Whitney (1965)

Comparar crianças com e sem

deficiência quanto

à imagem corporal, sentimentos de
32 pessoas entre 18-

53 anos de seis países. 15 com paralisia permanente e $17 \mathrm{em}$ recuperação. Solicitado DFH com roupa de praia.

Oito crianças

institucionalizadas e oito não institucionalizadas.

Oito crianças sem

deficiência como

grupo controle para

os dois experimentais.

Solicitado o DFH.

40 pessoas no grupo experimental. Não é indicado no resumo o $n$ do grupo controle. Utilizado o DFH

(Machover) e TAT.

24 crianças com paralisia cerebral (8-17 anos) e 23 crianças sem deficiência (5-6 anos). Utilizado o DFH (Goodenough) e o "copying mental age" (cópias de figuras geométricas). inadequação, agressão, hostilidade e inferioridade.

50 crianças para o grupo experimental e 50 para o grupo controle. Idade de 12 anos. Utilizado o DFH (Machover).
Grupo experimental com figuras menores; ambos representando a deficiência

diretamente; ambos apresentaram distorções nos membros inferiores; ambos apresentaram pouco movimento nos desenhos.

Grupo de crianças institucionalizadas tem maiores distúrbios na imagem corporal.

Ambos apresentaram dependência do ambiente; limites da imagem corporal indefinidos; falta de autodireção. Explicados por uma vivência sociocultural em que os participantes estavam inseridos.
DFH não expressa problemas na imagem corporal, mas problemas gerais para desenhar. Ambos expressam sinais que poderiam ser compreendidos como de pessoas com deficiência; sem diferenças significativas entre os grupos.

Crianças com deficiência apresentaram maior agressividade, tendo estas variações em relação à área afetada pela deficiência; deficiência expressa no desenho. 
Tabela 1 (continuação)

Síntese dos Resultados Obtidos

\begin{tabular}{|c|c|c|c|}
\hline Referência & Objetivo & Método & Resultados \\
\hline $\begin{array}{l}\text { *Nielsen } \\
\text { (1961) }\end{array}$ & $\begin{array}{l}\text { Comparar crianças } \\
\text { com e sem deficiência } \\
\text { quanto a nove itens } \\
\text { do DFH. }\end{array}$ & $\begin{array}{l}\text { Crianças com hemiplegia } \\
\text { e paraplegia. Não são } \\
\text { fornecidas outras } \\
\text { informações. Utilizado o } \\
\text { DFH (Goodenough). }\end{array}$ & $\begin{array}{l}\text { Sem diferença intergrupos. Intragrupos, } \\
\text { apenas crianças com hemiplegia } \\
\text { apresentaram maior exclusão das } \\
\text { extremidades em relação aos com paraplegia. }\end{array}$ \\
\hline $\begin{array}{l}\text { Silverstein } \\
\text { e Robinson } \\
(1956)\end{array}$ & $\begin{array}{l}\text { Verificar se os } \\
\text { DFHs expressam a } \\
\text { deficiência física. }\end{array}$ & $\begin{array}{l}22 \text { crianças com } \\
\text { poliomielite e } 44 \text { no grupo } \\
\text { controle. Idades entre } 9 \text { e } \\
12 \text { anos. Utilizado o DFH } \\
\text { (Machover). }\end{array}$ & $\begin{array}{c}\text { Mais de } 3 / 4 \text { representaram direta ou } \\
\text { indiretamente a deficiência no desenho. } \\
\text { Diferenças entre grupos não foi significativa. } \\
\text { Entre diferentes juízes, não foi possível } \\
\text { discriminar os grupos por meio do desenho. }\end{array}$ \\
\hline $\begin{array}{l}\text { *Noble, Price, } \\
\text { e Gilder } \\
(1954)\end{array}$ & $\begin{array}{c}\text { Indicar como a perda } \\
\text { de uma extremidade } \\
\text { ou de uma função } \\
\text { envolve problemas } \\
\text { emocionais além da } \\
\text { perda em si. }\end{array}$ & $\begin{array}{l}\text { Pessoas com deficiência } \\
\text { física congênita e } \\
\text { adquirida. } \\
\text { Não são fornecidas } \\
\text { outras informações. } \\
\text { Utilizado o DFH. }\end{array}$ & $\begin{array}{l}\text { Ambos apresentaram } \\
\text { ansiedade de separação, de castração e } \\
\text { impulsos agressivos. Bem como, presença } \\
\text { intensa de mecanismos de defesa. }\end{array}$ \\
\hline Abel (1953) & $\begin{array}{l}\text { Comparar o DFH de } \\
\text { pessoas mediamente } \\
\text { desfiguradas e } \\
\text { severamente } \\
\text { desfiguradas. }\end{array}$ & $\begin{array}{c}26 \text { pessoas mediamente } \\
\text { desfiguradas e } \\
19 \text { severamente } \\
\text { desfiguradas. 17-62 } \\
\text { anos. DFH (Machover) } \\
\text { e Rorschach antes } \\
\text { e depois de uma } \\
\text { intervenção cirúrgica. }\end{array}$ & $\begin{array}{l}\text { A maioria dos desenhos de ambos os } \\
\text { grupos expressaram a presença e ausência } \\
\text { da deformidade no desenho, indicando } \\
\text { que os do grupo com severa desfiguração } \\
\text { apresentaram uma imagem corporal } \\
\text { preservada, o que não se aplicou aos } \\
\text { mediamente desfigurados, indicando } \\
\text { maiores dificuldades emocionais. Ambos } \\
\text { expressaram falta de integração e } \\
\text { aceitação de si, inadequada identificação } \\
\text { sexual, medo do sexo e das relações } \\
\text { interpessoais, passividade, hostilidade e } \\
\text { forte dependência. }\end{array}$ \\
\hline $\begin{array}{l}\text { Machover } \\
(1949)\end{array}$ & $\begin{array}{l}\text { Apresentação da } \\
\text { técnica do DFH. }\end{array}$ & $\begin{array}{l}\text { Pessoas com deficiência } \\
\text { física. Utilizado o DFH } \\
\text { (Machover). }\end{array}$ & $\begin{array}{c}\text { A projeção nos desenhos variou em relação } \\
\text { ao grau de incapacidade e duração da } \\
\text { doença. DFH expressando diretamente } \\
\text { a deficiência. }\end{array}$ \\
\hline
\end{tabular}

Nota: DFH=desenho de figura humana; TAT=teste de apercepção temática.

avaliar a imagem corporal de pessoas com deficiência, mas por meio de questionários e com uma fundamentação teórica diferente, assim como uma concepção diferente de imagem corporal.

Quanto aos objetivos, foram criadas categorias para agrupar e discutir os artigos, a saber:

1. DFH da pessoa com deficiência física $(n=3)$;

2. comparações entre DFHs de diferentes quadros de deficiência $(n=6)$; e

3. problemáticas do DFH na avaliação de pessoas com deficiência $(n=3)$.

Foram encontrados ainda dois artigos de revisão da literatura (Van Kolck \& Van Kolch, 1972; Van Kolch, 1973) e um de apresentação da técnica (Machover, 1949), tal como indicado na tabela. Todos os artigos considerados para a revisão apresentam dados sobre DFH e deficiência física, e foram considerados pela abrangência do objetivo e pela pertinência à discussão.
Em relação ao método, observaram-se trabalhos com crianças e adultos, pertencentes a diferentes países e contextos sociais. Também se fazem presentes diferentes doenças e quadros que configuram uma deficiência física, bem como artigos tratando de deficiências adquiridas e congênitas. Os resultados serão discutidos adiante, seguindo a divisão das categorias apresentadas anteriormente. Ainda que diferentes entre si, cada categoria ilustra pontos de interesse na utilização do DFH em pessoas com deficiência física, mostrando os pontos de confluência presentes ao longo dos anos na literatura.

\section{Desenho da Figura Humana da pessoa com deficiência física}

Sistematizando os dados acerca de características que aparecem nos DFHs de pessoas com deficiência física, encontra-se a dissertação de Scherb (1998), que avaliou pessoas com lesão medular adquirida. Em relação à localização, foram encontrados desenhos na metade esquerda 
da folha, geralmente interpretados como ligação ao passado e à afetividade (Van Kolck, 1984; Machover, 1949). Trinta por cento da amostra apresentou desenhos considerados grandes, a maioria mostrou distúrbios na assimetria, indicando prejuízos na integração da imagem corporal. Há ainda transparências, rasuras e correções, indicando pontos conflitivos. Foi conferido destaque para a omissão de membros do corpo, bem como membros curtos e finos, e tamanho grande da cabeça, olhos, nariz e boca.

Na revisão de Van Kolck e Van Kolck (1972), há referência a trabalhos em que se observam as mesmas omissões e discrepâncias em relação aos membros, assim como a presença de órteses desenhadas nas figuras e junções impróprias com o tronco. De maneira semelhante, Silverstein e Robinson (1956) observaram em crianças com poliomielite aspectos como omissão, discrepância e apresentação não usual de membros inferiores. Também foi observada a presença de órteses, junção imprópria das pernas com o tronco. E, ainda, desenhos que não evidenciaram a presença de indicadores de deficiência, como os anteriormente citados.

Campos, Avoglia, e Custódio (2007) encontraram, em adultos com paraplegia adquirida, a divisão do corpo em partes, havendo uma separação marcada pela cintura, que de acordo com os autores, pode ser entendida pela própria configuração da paraplegia. A partir dos desenhos, os resultados são interpretados, discutindo a presença de desinteresse pelo sexo oposto, sentimentos de castração e impotência. Bem como, são apresentados mecanismos defensivos como a fuga na fantasia e racionalização. Enquanto discussão, os estudos apontam que, para as deficiências adquiridas, existe uma dificuldade de integração da imagem corporal. A condição física da deficiência, inserida em um contexto social no qual as tecnologias prometem corpos perfeitos, torna o processo ainda mais complexo, o que, para os autores, justifica pensar a deficiência como um problema social, além de um problema físico. Na pesquisa realizada por Noble, Price e Gilder (1954), o foco se encontra na perda de membros, que também é pontuada como presença de angústia de castração, sendo somada à ansiedade de separação, a impulsos agressivos e à intensa presença de mecanismos de defesa.

Observam-se semelhanças nos diferentes trabalhos, ainda que diferentes quadros e situações tenham levado à deficiência física. Como características regulares, pode-se apontar o aumento, a diminuição, a omissão ou o tratamento inusual dos membros, a divisão do corpo em parte superior e inferior em relação ao tronco, a angústia de castração e a presença de mecanismos defensivos. Os membros, considerados simbolicamente como vias de contato com o mundo (Van Kolck, 1984), encontram-se de alguma forma prejudicados, sendo indicativos não apenas de dificuldade de interação com o ambiente, mas também da possibilidade de utilização do corpo na busca por satisfação no ambiente. A respeito da divisão no tronco, é possível hipotetizar uma dificuldade na integração do corpo enquanto unidade. Tal possibilidade permite a coordenação de movimentos em prol de objetivos de maneira mais assertiva, podendo-se utilizar o corpo e suas funções de maneira integrada (Le Boulch, 2001). Sem essa integração, as dificuldades motoras já presentes podem acentuar os prejuízos funcionais.

Cabe citar ainda que é preciso cuidado no tratamento dos desenhos, visto que eles podem expressar uma condição análoga ao corpo real, às necessidades, aos sentimentos e às idealizações (Abel, 1953). Da mesma forma, nessas possibilidades, o desenho do mesmo sexo demonstrou fornecer representações diretas da pessoa, enquanto nos demais, representações das projeções conscientes e inconscientes (Abel, 1953; Johnson, 1972; Silverstein \& Robinson, 1956).

\section{Comparações entre Desenhos das Figuras Humanas de diferentes quadros de deficiência}

Partindo para diferenças entre grupos, Johnson (1972) comparou crianças com paralisia permanente e em recuperação (grupo experimental) a dois grupos sem deficiência, para controle. A instrução dada foi desenhar figuras com roupas de praia (sunga, biquíni, etc.). A justificativa para a utilização dessa instrução foi de que assim seria possível observar a representação das articulações do corpo. Foi verificado que o grupo experimental acrescentou maiores detalhes aos desenhos em relação ao grupo controle. Os que se encontravam em recuperação mostraram mais detalhes nos membros inferiores em relação ao outro grupo, e mais detalhes na cabeça em relação ao grupo controle. Os membros do grupo com paralisia permanente fizeram desenhos menores em relação ao grupo controle. Todos representaram distorções nos membros inferiores e superiores, podendo-se citar, inclusive, que os membros do grupo controle apresentaram maior número de distorções (tratamento inusual) que poderiam ser associadas a representações da deficiência no desenho. O grupo em recuperação mostrou menos movimento que o grupo controle, não havendo outras diferenças nesta categoria, o que contraria a hipótese inicial dos autores de que pessoas com paralisia permanente apresentam menos movimento no desenho. Explica, porém, a diferença de tamanho em ambos os grupos pela falta de sensações resultante da paralisia, o que dificultaria uma adaptação realística da imagem corporal e produziria imagens mais ambíguas.

Nielsen (1961) comparou DFHs de crianças com deficiência física (hemiplegia e paraplegia) e sem deficiência. Também não foram encontradas diferenças entre o grupo experimental e o grupo controle. Intragrupos, apenas crianças com hemiplegia apresentaram maior exclusão das extremidades em relação às com paraplegia. Manganyi (1972) comparou a imagem corporal de paraplégicos africanos hospitalizados e dois grupos controle (sem deficiência e não institucionalizados). As diferenças entre os grupos também não foram observadas, de modo 
que todos demonstraram dependência do ambiente, limites da imagem corporal indefinidos e falta de autodireção. A explicação dos autores perpassou as vivências socioculturais às quais todos os participantes estavam expostos. Sendo assim, as dificuldades encontradas não estariam restritas às pessoas com deficiência, mas abrageriam todos que compartilham desse contexto.

Wysocki e Whitney (1965) compararam adolescentes (ainda que citem crianças, estas tinham 12 anos) com e sem deficiência. Indicadores que discriminaram os grupos foram tamanho, posição na folha, sombreado, pressão, rotação da folha e tamanho da cabeça. O grupo com deficiência apresentou indicadores de agressividade e compensação negativa. Há ainda diferenças intragrupos em relação à variação do quadro que levou à deficiência. Weininger, Rotenberg e Henry (1972) compararam crianças com espinha bífida, institucionalizadas e não institucionalizadas. Como resultado, os autores apontam que as crianças institucionalizadas têm maiores distúrbios na imagem corporal em relação ao grupo controle.

Abel (1953) comparou pessoas mediana e severamente desfiguradas, antes e depois de intervenção cirúrgica de correção. Em sua maioria, os desenhos diferenciaram os grupos, indicando que aqueles com severa desfiguração apresentam uma imagem corporal preservada, diferente dos medianamente desfigurados, o que também pode ser indicativo de maiores dificuldades emocionais. Ambos expressaram falta de integração e aceitação de si, inadequada identificação sexual, medo da relação sexual e das relações interpessoais, passividade, hostilidade e forte dependência.

$\mathrm{Na}$ maioria dos trabalhos, não foram encontradas diferenças entre grupos, inclusive com e sem deficiência. Tal dado permite conjecturar algumas hipóteses iniciais, seguindo a proposta teórico-metodológica do instrumento. Segundo Silverstein e Robinson (1956), a expressão de um desenho com características consideradas de pessoas com deficiência não é uma exclusividade dessa população. Tais características podem ser vistas em pessoas sem deficiência que se encontrem em conflito psicológico a ponto de haver uma mesma representação em seu DFH. Pode-se hipotetizar o mesmo acerca de pessoas com deficiência, bem integradas aos seus corpos, produzindo figuras cuja imagem corporal encontra-se tal qual a de alguém sem deficiência. Nesse ponto, os dados permitem considerar que quando não há integração da imagem corporal, e a experiência com a deficiência é vivenciada como conflitiva, encontram-se maiores alterações nos desenhos. Desse modo, o DFH ilustra que tal parte do corpo, em sua assunção simbólica, guarda problemáticas para o psiquismo daquele sujeito. Por outro lado, para os que realizam uma integração, essas questões carecem de importância, e o desenho se apresenta de forma menos alterada (como rasuras, correções, aumento, diminuição, omissão, etc.). Entretanto, outras considerações serão feitas a seguir, para além da fundamentação do instrumento.

\section{Problemáticas do Desenho da Figura Humana na avaliação de pessoas com deficiência}

Alguns autores passaram a questionar como a presença de dificuldades motoras poderia prejudicar a realização dos desenhos e tal prejuízo ser interpretado erroneamente como um distúrbio da imagem corporal. Desse modo, Abercrombie e Tysin (1966) compararam o DFH com a cópia de figuras geométricas ("copying mental age”). Do ponto de vista cognitivo, os resultados apontaram menor idade mental em relação à cronológica no grupo com deficiência no copying mental age. $\mathrm{O}$ resultado do DFH foi semelhante, porém com valores mais elevados. O mesmo ocorreu no grupo controle. Os autores afirmam não ser possível atribuir as dificuldades no DFH a uma desordem na imagem corporal. Do ponto de vista projetivo, citando o arcabouço teórico de Machover, a expressão da imagem corporal é questionada, indicando desenhos de crianças sem deficiências que apresentam DFHs com as mesmas características, tal como visto anteriormente. Desse modo, compreende-se que tratamentos inusuais nas figuras humanas estariam presentes em outras produções gráficas, não sendo uma exclusividade do DFH. No entanto, não seria possível afirmar que as alterações no DFH refletem necessariamente as alterações na imagem corporal dessas pessoas.

Nessa mesma linha, Krampen (1985) parte de uma sistematização presente na literatura que indica que desenhos infantis são baseados em três conjuntos de grafemas que começam a se desenvolver no fim do terceiro ano e vão até o quinto ano de vida. São formas simples compostas para formar os desenhos, que vão se desenvolvendo de acordo com o aumento do controle muscular e visuoespacial. No primeiro grupo estão as modulações rotativas e translativas, as espirais e os traços angulares. No segundo, as intersecções e os traços repetitivos são reduzidos na mesma direção. E no terceiro se fazem presentes os grafemas simétricos, adquiridos pela projeção dos eixos (vertical e horizontal) do corpo da criança no papel, permitindo construir formas com propriedades simétricas. Com esse modelo, o autor comparou desenhos de crianças com e sem deficiência física. Assim, foi observado que as crianças com deficiência desenharam grafemas até o segundo estágio, ainda que estivessem em idade cronológica suficiente para realizar um desenho com grafemas do terceiro estágio. Tal dado indica que crianças com deficiência possuem um atraso nesse processo de desenvolvimento, diminuindo o número de grafemas possíveis. A explicação dada pelo autor se encontra em um prejuízo da imagem corporal por conta da deficiência, o que prejudicaria a passagem para os desenhos simétricos, e logo, prejudicaria também a passagem para os desenhos mais complexos.

O mesmo foi observado em Silverstein e Robinson (1956), sendo interessante relatar sua pesquisa pormenorizadamente, pois dá indicadores de pontos a serem considerados. Primeiramente, os autores comparam crianças 
com e sem deficiência pareando-as quanto ao sexo, à idade, à escolaridade e à escola que frequentavam. Foram encontradas algumas diferenças, como tratamentos inusuais dos membros e presença de próteses, porém elas indicam que os juízes que avaliaram os desenhos tinham conhecimento acerca das especificidades das deficiências dos participantes. Nesse procedimento introduz-se um viés de duas formas: sobrecarregando o peso de pequenos desvios como sendo representações de deficiências; e não considerando dados que não estavam relacionados ao quadro da deficiência conhecida. A dificuldade da falta de uma sistematização nesse campo acerca da frequência com que indicadores de deficiência aparecem na população em geral e na população em questão é pontuada. Desse modo, tornam-se inválidas análises que relacionam determinados traços a grupos com condições orgânicas específicas. Com esse argumento, são citadas pesquisas em que houve maiores cuidados metodológicos (como controle da amostra quanto à sua homogeneidade), não sendo encontradas diferenças significativas. Esse dado insere outra problemática: a possibilidade de amostras homogêneas nessa população. Consideradas as diferenças em localizações, graus e extensões das deficiências, os resultados serão diferentes, tal como já havia indicado Machover (1949), o que faz com que o pesquisador seja seletivo nas análises.

Adiante, Silverstein e Robinson (1956) empreendem a segunda parte do estudo, que consistiu em definir itens que, a priori, representariam a deficiência, estabelecendo graus que a especificassem no traçado do desenho. No caso, com base na literatura, foram escolhidos, dentre outros, o tratamento dos membros, o tamanho e a posição da folha. Nesse modo de avaliação dos dados, não foram encontradas diferenças entre os grupos. Contudo, tal resultado serve apenas de especulação crítica, pois os itens selecionados também partiram de uma consideração a priori em relação às pessoas com deficiência que não necessariamente seriam válidos. Adiante, a última parte reuniu todos os desenhos produzidos, sendo solicitado que os juízes, sem conhecimento da amostra, selecionassem 22 figuras feitas por pessoas com deficiência. $\mathrm{O}$ acerto dos juízes foi de 52 a $64 \%$, não sendo significativamente maior que o acaso. Por todos os dados apresentados, Silverstein e Robinson (1956) criticam a prática projetiva de Machover e sustentam a posição de Goodenough. Esta considera que apenas depois dos 12 anos o desenho permite avaliar a personalidade, o interesse e os temperamentos, e que é possível apenas verificar as projeções da atitude em relação ao ambiente, projeções do ideal da própria imagem, ou o resultado de circunstâncias externas. Desse modo, o artigo considerou corpo físico, imagem corporal e DFH como isomórficos, sendo que esta relação, em uma consideração cuidadosa, não o é. Ao final, a utilidade do instrumento para a aplicação individual não é descreditada. Os autores indicam que o DFH permite avaliar a experiência corporal da pessoa com deficiência, desde que considerados os cuidados metodológicos citados. Tal artigo é de grande valia, pois além de apontar uma problemática delicada do uso do instrumento nessa população, indica também formas de contorná-la. Com isso, podemos concluir que o uso de indicadores preestabelecidos e de juízes blindview permite evitar os vieses no uso do instrumento, sendo uma consideração importante para outras pesquisas. A esse respeito, para uma avaliação, considera-se a necessidade de se atentar ao recurso motor, inserindo a condição orgânica como um dado, sem pressupor, no entanto, que as condições da deficiência são condicionadas a prejuízos na imagem corporal do sujeito. Trata-se de se considerar a singularidade de cada caso, do contrário, haveria o risco de se relacionar diretamente determinados traços a quadros específicos.

Vale citar que os autores comentam a falta de consenso a respeito do conceito de imagem corporal a ser avaliado pelo DFH. Na sistematização dos resultados, existem menções ao termo "esquema corporal" e concepções de imagem corporal como uma representação fiel da disposição do corpo orgânico. Essa dificuldade também se faz presente, por exemplo, na obra de Schilder (1950/1980), em que os termos "imagem corporal", "esquema corporal" e "modelo postural" são intercambiados. Essa falta de rigor do conceito pode provocar desencontros, inclusive do ponto de vista metodológico. É preciso estabelecer um consenso acerca do conceito de imagem corporal, e acerca do próprio instrumento, sobre o que ele se propõe a avaliar, evitando, assim, que pesquisas com objetivos diferentes, ainda que utilizando os mesmos termos, sejam compreendidas dentro de suas propostas.

Nessa exposição, a imagem corporal perpassa as atitudes em relação ao ambiente, ao ideal de autoimagem e às circunstâncias do meio. Por essa perspectiva, torna-se menos importante saber se uma pessoa com deficiência projeta a si mesma em um desenho em relação à vivência subjetiva presente, podendo se expressar a seu modo em um desenho. Ao contrário, seria possível inverter a situação e dizer que pessoas com capacidades artísticas possuem uma imagem corporal preservada em todos os casos. Aponta-se a necessidade do olhar clínico e da atenção aos diferentes dados que compõem um caso durante uma avaliação.

Por essa razão, Van Kolck (1973) postula que o desenho seja considerado em contexto singular e com a presença de outros instrumentos que forneçam diferentes fontes de dados. Cabe citar também que o Conselho Federal de Psicologia (CFP, 2013), em nota de 25 de fevereiro de 2013, atenta para alguns pontos, a fim de manter a qualidade dos instrumentos de avaliação com pessoas com deficiência: adaptar um teste não se resume a alterar indistintamente um componente sem que se avalie suas consequências. É preciso verificar se a adaptação não modifica o constructo a ser avaliado. Assim como conhecer previamente a especificidade da deficiência da pessoa a ser avaliada permite um uso adequado dos instrumentos. 
Por fim, é recomendada a avaliação prévia das modificações nos instrumentos em pessoas com deficiência ou a consulta a profissionais para tal. Desse modo, é indicada a produção de pesquisas que corroborem uma prática que evite vieses ou dados inválidos.

\section{Considerações finais}

Em termos de considerações finais, este artigo buscou revisar e analisar a literatura da avaliação por meio do desenho da figura humana em pessoas com deficiência física. Verificou-se a utilização do desenho enquanto procedimento gráfico e suas especificidades em relação à figura humana e à imagem corporal. Foi possível discutir aspectos projetivos nos desenhos, apontando importantes características presentes nessa população, como disjunção do tronco e tratamento inusual das extremidades. Tal dado pode ser tratado em uma vertente projetiva, considerando as dificuldades de integração, o contato com o ambiente e a independência, assim como indicativos de prejuízos motores e da imagem corporal em que o componente orgânico é parte. Pelo caminho percorrido, pode-se hipotetizar que os prejuízos funcionais na deficiência não se encontram apenas na esfera biológica, de modo que os tratamentos oferecidos se beneficiariam em considerar a relação do sujeito com deficiência com seu corpo e a dinâmica da imagem corporal.

Por meio do uso do DFH, é possível acessar níveis do psiquismo que, por outro instrumento, não seria possível. $\mathrm{Na}$ representação gráfica do corpo, a partir dos esquemas concretos e simbólicos, é possível detectar a relação entre os prejuízos orgânicos e sua representação. Pelos dados, foi possível apreender que uma alteração no organismo não é obrigatoriamente uma alteração no nível psíquico e, para o movimento, ambos os corpos - orgânico e representado — são necessários. Desse modo, determinados quadros posturais e movimentos específicos são um produto dessas interações. No campo da deficiência, em que o aspecto orgânico é o foco dos tratamentos, o DFH pode produzir dados clínicos úteis para o psicólogo, seja em seu trabalho individual ou em equipe.

Conclui-se que o DFH parece constituir instrumento que contribui para intervenções em pessoas com deficiência, mas seu uso, assim como no caso dos demais instrumentos, deve ser acompanhado por um olhar e um raciocínio clínico para uma avaliação adequada. São necessárias novas pesquisas, principalmente que estabeleçam um consenso quanto ao objeto da avaliação, haja vista a indefinição da literatura acerca da imagem corporal, ou mesmo do que se avalia no DFH - personalidade, esquema/representação corporal ou imagem corporal. Desse modo, o artigo procurou oferecer um arcabouço conceitual e uma discussão que visam contribuir para a sistematização dos termos.

Como visto, a literatura sobre DFH nessa população carece de atualização, de modo que pesquisas futuras poderão recuperar as propostas, inclusive partindo dos avanços alcançados até então. Por se tratar de uma técnica não dispendiosa e de simples aplicação, e, nesse sentido, importante em uma realidade carente de recursos na área da saúde, parece plausível o investimento em sua consolidação. O investimento no ensino e na utilização dessa técnica possivelmente contribuirá para o retorno do parecer favorável no Sistema de Avaliação de Testes Psicológicos (SATEPSI), pelo Conselho Federal de Psicologia, para sua utilização na prática clínica como técnica projetiva.

\section{Referências $^{4}$}

^Abel, T. M. (1953). Figure drawings and facial disfigurement. American Journal of Orthopsychiatry, 23(2), 253-264. doi: 10.1111/j.19390025.1953.tb00054.x

^Abercrombie, M. L. J., \& Tyson, M. C. (1966). Body Image and Draw-a-Man Test in Cerebral Palsy. Developmental Medicine E Child Neurology, 8(1), 9-15. doi: 10.1111/j.1469-8749.1966.tb08267.x

Andrade, M. O. P. E. M. (2014). A técnica projetiva no diagnóstico da personalidade: como eu me vejo? Como o mundo me vê?Como realmente é? Campo Grande: Autor.

*Campos, M. T. de, Avoglia, H. R. C., \& Custódio, E. M. (2007). A imagem corporal de indivíduos com paraplegia não congênita: um estudo exploratório. Psicólogo informação, 11(11), 27-55. doi: 10.15603/2176-0969/pi.v11n11p27-55

Conselho Federal de Psicologia (2013). CFP divulga orientações para avaliação psicológica de pessoas com deficiência. Nota técnica, 25 de fevereiro de 2013. Recuperado em 20 de setembro, 2015, de http://www.crpsp.org.br/portal/midia/fiquedeolho_ver.aspx?id=578.

Dolto, F. (2015). A imagem inconsciente do corpo (3 ed.). São Paulo: Perspectiva (Trabalho original publicado em 1984).

$\star$ Johnson, F. A. (1972). Figure drawings in subjects recovering from poliomyelitis. Psychosomatic Medicine,34(1), 19-29.

$\star$ Krampen, M. (1985). Grapheme development in handicapped children's drawings. Perceptual and Motor Skills, 60(1), $231-238$.

Le Boulch, J. (2001). O desenvolvimento psicomotor: do nascimento até os 6 anos (7a ed.). Porto Alegre: Artmed.

* Van Kolck, O. L., \& Van Kolck, T. (1972). O desenho da figura humana em casos especiais. Boletim de Psicologia, 24(64), 89-121.

*Van Kolck, O. L. (1973). O desenho da figura humana no estudo de problemas específicos. Boletim de Psicologia, 25(64), 151-181.

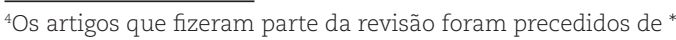


Van Kolck, O. L. (1984). Testes projetivos gráficos no diagnóstico psicológico. São Paulo: Pedagógica e Universitária.

Macedo, P. C. M. (2008). Deficiência física congênita e Saúde Mental. Revista da Sociedade Brasileira de Psicologia Hospitalar, 11(2), $127-139$.

*Machover, K. (1949). Proyección de la personalidad en el dibujo de la figura humana. Havana: Cultural.

*Manganyi, N. C. (1972). Body image boundary differentiation and self-steering behavior in African paraplegics. Journal of Personality Assessment, 36(1), 45-49. doi: 10.1080/00223891.1972.10119728

Nasio, J. -D. (2009). Meu corpo e suas imagens. Rio de Janeiro: Jorge Zahar.

$\star$ Nielsen, H. H. (1961). Human figure drawings by normal and physically handicapped children: Draw-a-Person Test. Scandinavian Journal of Psychology, 2(1), 129-138. doi: 10.1111/j.1467-9450.1961.tb01230.x

^Noble, D., Price, D. B., \& Gilder Jr., R. (1954). Psychiatric disturbances following amputation. American Journal of Psychiatry, 110(8), 609613. doi: 10.1176/ajp.110.8.609

*Scherb, E. M. V. K. (1998). Deficiência física adquirida por lesão medular traumática: estudo da auto-imagem. Dissertação de mestrado , Universidade de São Paulo, São Paulo.

Schilder, P. (1980). A imagem inconsciente do corpo (R. Wertman, Trad.). São Paulo: Martins Fonte (Trabalho original publicado em 1950).

$\star$ Silverstein, A. B., \& Robinson, H. A. (1956). The representation of orthopedic disability in children's figure drawings. Journal of Consulting Psychology, 20(5), 333-341. doi: 10.1037/h0042868

afísica. Revista Colombiana de Psicología, 24(1), 219-233. doi: 10.15446/rcp.v24n1.45644

*Weininger, O., Rotenberg, G., \& Henry, A. (1972). Body image of handicapped children. Journal of Personality Assessment, $36(3), 248-253$. doi: 10.1080/00223891.1972.10119752

*Wysocki, B. A., \& Whitney, E. (1965). Body image of crippled children as seen in draw-a-person test behavior. Perceptual and Motor Skills, 21(2), 499-504. doi: 10.2466/pms.1965.21.2.499

\section{Sobre os autores}

Diego Rodrigues Silva é Psicólogo e Mestrando do Programa de Pós-Graduação em Psicologia Clínica pela Universidade de São Paulo. Bolsista da CAPES.

Eliana Herzberg é Psicóloga, possui Doutorado em Psicologia Clínica pela Universidade de São Paulo e título de livre docente pelo Instituto de Psicologia da USP. Atualmente é Professora Associada do Departamento de Psicologia Clínica pelo Instituto de Psicologia da USP. 